\title{
THE SURVIVAL IMPACT OF COMBINED EXPRESSION OF MYC, BCL2 AND BCL6 IN DIFFUSE LARGE B CELL LYMPHOMA PATIENTS
}

\section{Adelina BIRCEANU COROBEA ${ }^{1}$, Anca EVSEI ${ }^{1}$, Cristian ROSIANU ${ }^{2}$, Mircea GHEORGHE ${ }^{3}$, Gabriela BIRCEANU ${ }^{1}$, Narcis COPCA ${ }^{4}$, Maria SAJIN ${ }^{5}$, Anca LUPU ${ }^{6}$}

${ }^{1}$ Department of Pathology, „Sfanta Maria“ Clinical Hospital, Bucharest, Romania

2 Department of Gastroenterology, „Sfanta Maria“ Clinical Hospital, Bucharest, Romania

${ }^{3}$ Department of General and Esophageal Surgery, „Sfanta Maria“ Clinical Hospital, „Carol Davila“ University of Medicine and Pharmacy, Bucharest, Romania

${ }^{4}$ Department of Surgery, „Sfanta Maria“ Clinical Hospital, Bucharest, Romania

${ }^{5}$ Department of Pathology, Emergency Universitary Hospital, „Carol Davila“ University of Medicine and Pharmacy, Bucharest, Romania

${ }^{6}$ Department of Hematology, „Coltea“ Clinical Hospital, „Carol Davila“ University of Medicine and Pharmacy, Bucharest, Romania

Received 02 Mar 2018, Accepted 06 May 2018

\section{Abstract}

Introduction. C-MYC is one of the essential transcription factors that play a role in various cellular functions. The MYC rearrangement is associated with low overall survival and low progression-free survival, increased risk of central nervous system disease relapse in patients diagnosed with diffuse large B cell lymphoma (DLBCL) and treated with R-CHOP. Also, c-MYC amplification is an unfavorable prognostic factor, amplified by BCL2 and BCL6 rearrangements, respectively, designating lymphomas as high grade according to the WHO 2016 revision.

Objectives. We search the correlations of the double or triple expression of C-MYC and BCL2 and/or BCL6 markers, with clinical survival data.

Methods. A cohort of 80 patients with DLBCL was examined for MYC, BCL2 and BCL6 immunohistochemical expression.

\section{RÉSUMÉ}

L'impact de l'expression combinée de MYC, BCL2 et BCL6 sur la survie des patients atteints de lymphome diffus à grandes cellules $\mathrm{B}$

Introduction. C-MYC est l'un des facteurs de transcription essentiels qui jouent un rôle dans diverses fonctions cellulaires. Le réarrangement MYC est associé à une faible survie globale et une faible survie sans progression, un risque accru de rechute du système nerveux central chez les patients diagnostiqués avec un lymphome diffus à grandes cellules B (DLBCL) et traités par R-CHOP. En outre, l'amplification c-MYC est un facteur pronostique défavorable, amplifié par les réarrangements BCL2 et BCL6, respectivement, désignant les lymphomes de haut degré selon la révision de 2016 de l'OMS.

Objectifs. Nous recherchons les corrélations de l'expression double ou triple des marqueurs c-MYC et 
Results. Six, respectively four, patients of the total cohort were MYC/BCL2 and MYC/BCL6 positive and only 3 were MYC/BCL2/BCL6 triple positive. The median overall survival was 6 months, $95 \%$ confidence interval (CI)) for triple expression and 13 months (CI 95\%) for MYC/BCL2, respectively MYC/BCL6 dual expression. Complete therapeutical response was registered in 2 patients with triple expression and 4, respectively 2 patients, with MYC/BCL2 and BCL6 dual expression. Relapse was registered in 1 patient, either $\mathrm{MYC} / \mathrm{BCl} 2$ dual positivity respectively triple positivity, and in 2 patients with MYC/BCL6 positivity.

Conclusions. Our study has showed that the double and triple positivity expression in DLBCL have a low incidence (15\%) and are correlated with poor survival, the prognosis being unfavorable.

Keywords: DLBCL, MYC/BCL2/BCL6, double triple expression, survival.

\section{INTRODUCTION}

Non-Hodgkin's malignant lymphoma is currently the most common malignant hematological disease, with constant incidence over the years.

The term „diffuse large B cell lymphoma" (DLBCL) covers a heterogeneous group of lymphomas characterized by a diffuse proliferation composed of large B cells. This category includes less common subtypes, such as large B cell lymphoma (thymic), intravascular B lymphoma and primary effusion lymphomas. This type of lymphoma may arise primarily in a lymph node or extra-lymph node and it may appear de novo or represent a transformation of a low grade lymphoma, Hodgkin's lymphoma predominant nodular lymphocytes, non-Hodgkin's lymphoma and chronic lymphocytic leukemia (Richter's syndrome) $)^{1-3}$.

Diffuse large B cell lymphoma is a monoclonal lymphocytic proliferation exhibiting both clinically and biologically marked heterogeneity. Most of these lymphomas originate in lymph nodes, but $\leq 40 \%$ of cases have primary extra-lymph node location. From a molecular, history and clinical presentation point of view, diffuse large B-cell lymphomas are distinct entities $^{4,5}$.
BCL2 et / ou BCL6, avec des données cliniques de survie.

Méthodes. Un lot de 80 patients atteints de DLBCL a été examiné pour l'expression immunohistochimique MYC, BCL2 et BCL6.

Résultats. Six patients et 4 patients de la cohorte totale étaient double positifs, respectivement MYC/ BCL2 et MYC/BCL6 positifs et seulement 3 étaient MYC/BCL2/BCL6 triple positifs.La survie globale médiane était de 6 mois (intervalle de confiance à 95\% (IC)) pour la triple expression et de 13 mois (IC 95\%) pour la double expression MYC/BCL2 respectivement MYC/BCL6. Une réponse thérapeutique complète a été enregistrée chez 2 patients ayant une triple expression et 4 respectivement 2 patients avec expression double MYC/BCL2 et BCL6. Une rechute a été enregistrée chez 1 patient avec une double positivité MYC/ $\mathrm{BCl} 2$ respectivement triple positivité et chez 2 patients avec une positivité MYC/BCL6.

Conclusions. Selon la littérature, notre étude a montré que la double et la triple expression de positivité dans le DLBCL ont une faible incidence (15\%) et sont associées à une faible survie, le pronostic étant défavorable.

Mots-clés: DLBCL, MYC / BCL2 / BCL6, double triple expression, survie.

Depending on the gene expression profile (GEP), two distinct biological groups according to cellular origin are identified: germinal center subtype (GCB) and activated cell subtype (ABC). Taking into consideration this classification, there is a small subgroup which does not belong to these two categories. Patients with ABC subtype have a higher risk of not responding to modern therapies, thus becoming a subgroup in the advanced risk group in the rituximab era of unknown clinical significance, but with a good response to the new therapeutic strategies (bortezomib, lenalidomide or ibrutinib) ${ }^{6-8}$.

C-MYC is one of the essential transcription factors that play a role in various cellular functions including proliferation, growth and apoptosis, cell cycle, adhesion, cellular metabolism, mitochondrial function and survival. The proto-oncogene c-MYC, located on chromosome $8 \mathrm{q} 24$, is one of the most common genes involved in human carcinogenesis ${ }^{8-9}$.

C-MYC rearrangements are identified in 5-15\% of DLBCL NOS cases ${ }^{8-10}$, but protein expression is identified in a larger percentage, of approximately $30-50 \%$ of DLBCL cases $^{11,12}$, representing other mechanisms of activation of c-MYC expression, such as amplification or mutation of microRNA. The MYC rearrangement is associated with overall survival and 
low progression-free survival, increased risk of central nervous system disease relapse in patients treated with R-CHOP'13-15.

Also, c-MYC amplification is an unfavorable prognostic factor, amplified by BCL2 and BCL6 rearrangements, respectively. The double-hit (DHL) and the triple-hit (THL) show both c-MYC and BCL2 and/or BCL6 rearrangements, and the latter presents all three rearrangements, designating lymphomas as high grade according to the WHO 2016 revision ${ }^{15-19}$.

DHL refers to both DHL and THL, BCL2 rearrangements occurring in $80-90 \%$ of cases, while BCL 6 rearrangements represent only 5\% of DHL / THL cases; THL represents $8 \%$ of all DHL / THL. DHL represents $10 \%$ of all DLBCLs and 20\% of high grade lymphomas transformed from a small cell lymphoma B. Patients with DHL have a poor prognosis, independent of IPI, being refractory to chemotherapy and dying within the first year since diagnosis.

FISH is the gold standard for DHL diagnosis; approximately $93 \%$ of total $\mathrm{DHL}$ originate in the germ center and express CD 10, but those with c-MYC and BCL 6 rearrangements are CD 10 negative, IRF4/ MUM1 positive, less BCL 2 positive and less complex cytology. DHL with c-MYC/ BCL2 rearrangements shows a TP53 mutation in intermediate lymphomas between DLBCL and Burkitt's lymphoma, whereas in DHL with c-MYC/ BCL 6 rearrangements this mutation is missing; the accumulation of chromosomal changes that interest this additional gene, c-MYC, BCL2 and BCL6, have an important prognostic role $^{17,19}$.

Interaction of BCL 6 with post-transcriptional regulatory mechanisms (ex CREBBP/ EP300) ${ }^{20}$ and FBX011 mutation, represents a positive transcriptional regulator in $5 \%$ of cases $^{21}$.

Chromosomal location of the BCL 6 locus is present in over $35 \%$ of DLBCL. BCL6 is a transcriptional inhibitor that binds specific target gene promoter sequences, modulating their expression by interacting with distinct co-inhibitory complexes ${ }^{22}$.

BCL 6 plays an essential role in lymphoma genesis, representing a therapeutic target through BCL6 inhibitory molecules with potential anti-lymphoma activity, and also has a strong synergy in combination with other therapies ${ }^{23-25}$.

In the current practice for this classification, the most widely used diagnostic algorithm is the Hans algorithm. The Hans algorithm uses three markers (CD 10 positive marker for the germinal center, BCL6 marker useful for germinal center and non-germinal center, MUM1 marker for post germinal center). According to this algorithm, large cell diffuse lymphoma is divided into the CGB (germinal center cell) and non-CGB subtype (activated cell) ${ }^{26}$.
The double-hit and triple-hit lymphomas are characterized by chromosomal rearrangements of both MYC and BCL2 or BCL6, the prognosis being unfavorable, but with a low incidence (15\%). Immunohistochemical analysis of overexpression of both MYC and BCL2/BCL6 has significant prognostic significance. Overexpression of the two or three markers may occur in the absence of chromosomal rearrangements $\mathrm{s}^{27,28}$.

The obJective OF THE StudY was to search the correlations of the double or triple expression of c-MYC and BCL2 and/or BCL6 markers, with clinical survival data of patients with diffuse large B cell lymphoma.

\section{Material AND MEthods}

\section{Patient selection}

We included 80 patients diagnosed with diffuse large B cell lymphoma treated in the Hematology Department of the Coltrea Clinical Hospital, Bucharest, over a 5 years period of time, treated with RCHOP (rituximab, cyclophosphamide, doxorubicin, vincristine, and prednisone). The histopathological and immunohistochemical studies were carried out in the Department of Pathology of Coltea Clinical Hospital and of Emergency University Hospital of Bucharest.

Tissue collection and pathological review

We performed IHC assays to evaluate CD10, MUM1, BCL6, BCL2 and c-MYC expression to further classify these tumors. As part of this Registry effort, an experienced pathologist centrally reviewed hematoxylin-eosin slides for all patients in order to confirm histological classification and record standard pathological features. The following antibodies and dilutions were used: CD 10 (Novocastra dilution of $1: 60$ ), MUM1 (Novocastra dilution of 1:100), BCL6 (Novocastra dilution of 1:50), BCL2 Novocastra dilution of 1:150), c-MYC (Cell Marque dilution of 1:150). Percentage and intensity of stained tumor cells were scored according to Remmele ${ }^{29}$.

The immunohistochemical stains were counted at tumor hotspots (positive nuclei/100 cells, documented in percentage), CD 10 and BCL 6 were considered positive when more than $30 \%$ of the hotspots were positive, MUM 1 was positive in over $40 \%$ of the hotspots, BCL2 was positive in over $50 \%$ of the hotspots, MYC was considered positive in over $40 \%$ of the diagnostic hotspots.

Patient's material was anonymous and the study was approved by the Ethical Committee of the Coltea Clinical Hospital and was performed according to the standards established in the Declaration of Helsinki. 


\section{Statistical Methods}

Analyses were performed with R and STATIS. TICS programs. For univariate analysis, the Likelihood Ratio, Fisher exact tests, Mann-Whitney, were used to compare the continuous and discontinuous variables. Survival analysis was performed using the Kaplan-Meier method compared to the log-rank test.

\section{Results}

\section{Comparison of clinical and pathological fea- tures}

After histopathological review, 80 patients were included in the study (Table 1). Tumors were collected from 41 male and 39 female, with ages between

Table 1. Clinico-pathological features of the cohort

\begin{tabular}{|c|c|c|}
\hline Histopathological subtype & $\mathrm{N}($ total $) \%$ & p-value \\
\hline Germinal cell center & $33(41.2 \%)$ & \\
\hline Non germinal cell center & $39(51.3 \%)$ & \\
\hline \multicolumn{3}{|l|}{ Sex distribution } \\
\hline Female & $39(48.8 \%)$ & \\
\hline Men & $41(51.2 \%)$ & \\
\hline \multicolumn{3}{|l|}{ Age } \\
\hline minimum & 19 years & \\
\hline medium & 57,26 years & \\
\hline maximum & 87 years & \\
\hline \multicolumn{3}{|l|}{ Ann Arbor Stage } \\
\hline Stages I-II & $30(37.5 \%)$ & \\
\hline Stages III- IV & $50(62.5 \%)$ & \\
\hline \multicolumn{3}{|l|}{ B Symptoms } \\
\hline yes & $44(55 \%)$ & \\
\hline no & $36(45 \%)$ & \\
\hline \multicolumn{3}{|l|}{ Bulky disease } \\
\hline yes & $25(31.3 \%)$ & \\
\hline no & $55(68.2 \%)$ & \\
\hline \multicolumn{3}{|l|}{ Therapeutic response } \\
\hline complete & $47(58.8 \%)$ & \\
\hline partial & $9(11.3 \%)$ & \\
\hline non-responsive & $24(30 \%)$ & \\
\hline \multicolumn{3}{|l|}{ Relapse } \\
\hline yes & $24(30 \%)$ & \\
\hline no & $56(70 \%)$ & \\
\hline
\end{tabular}

19 years old and 87 years old with an average of 57.26 years old.

In log rank test and univariate COX analysis, patients had poorer $\mathrm{OS}$ in the female cohort, higher clinical performance status (ECOG) and a better outcome in patients who received Rituximab in their treatment.

The presence of B symptoms (weight loss, profuse sweating and fever without infectious causes) is considered an unfavorable prognostic factor. 44 of the patients in the study group (55\%) had B symptoms, the remaining 36 patients (45\%) being asymptomatic.

Based on the findings of Ann Arbor stage, there is an apparent prevalence of $63.3 \%$ disseminated disease versus $36.7 \%$, a phenomenon that could be interpreted in the context of a delayed presentation of patients to the doctor or possible delays of diagnosis for this type of lymphoma due to lack of experience or lack of technical resources. Patients with early clinical stages (stage I and II) had better outcome than patients with advanced clinical stages (stage III and stage IV). Four of them registered death until the end of the study.

Of all the patients in the present study, 25 had a bulky disease and had registered 3 deaths; there was only one death in patients without bulky disease. Correlation of clinical aspects (survival) of the two cohorts, a statistically significant difference is obtained $(\mathrm{p}$ value $=0.007)$. According to the Hans algorithm, there were 33 patients diagnosed with germinal center (CGB) and 39 cells with activated/ non-germinal center (non-CGB).

The complete therapeutic response was recorded in 47 patients, representing just over half (58.8\%) of the cases, while 24 responded partially, and the remaining $11.3 \%$ were non-responsive.

The relapse was recorded in 24 of the patients, representing $30 \%$ and the rest, approximately three quarters, respectively 56 patients, did not show relapse.

\section{Comparison of immunohistochemical staining of MYC, BCL2 and BCL6}

Six of the total patients included in the study had MYC and BCL2 positivity, 2 of which had 2 deaths, $8,5 \%$ presenting complete therapeutic response and

Table 2. Association of dual and triple positivity (MYC/BCL6/BCL2)

with treatment-related events and overall survival

\begin{tabular}{ccccccc}
\hline & N & Relapse & \multicolumn{3}{c}{ Therapeutic response $\%$} & Events $\%$ \\
\hline MYC/BCL2 & 6 & 1 & 4 & Complete response & Partial response & Non responsive \\
\hline MYC/BCL6 & 4 & 2 & 2 & 1 & 1 & 2 \\
\hline MYC/BCL2/BCL6 & 3 & 1 & 2 & 1 & 1 & 3 \\
\hline
\end{tabular}




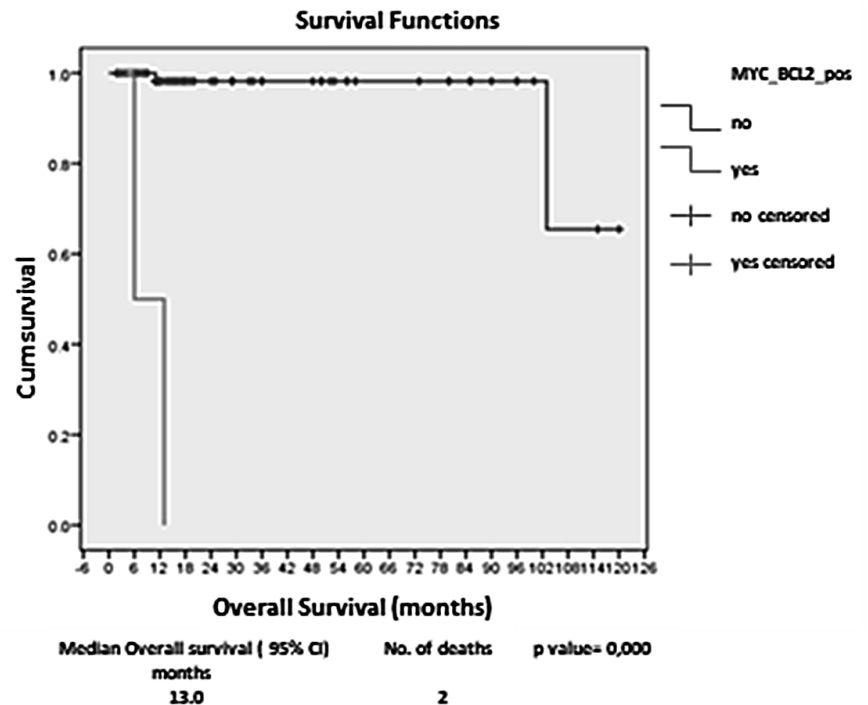

Figure 1. MYC/ BCL6 Kaplan Meyer curve for Overall Survival

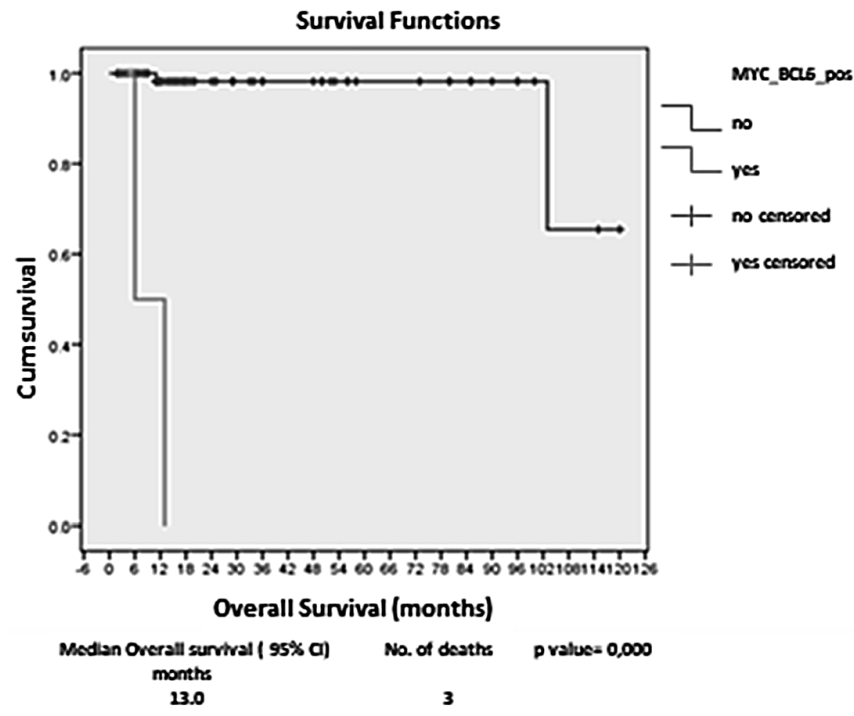

Figure 2. MYC/ BCL6 Kaplan Meyer curve for overall survival

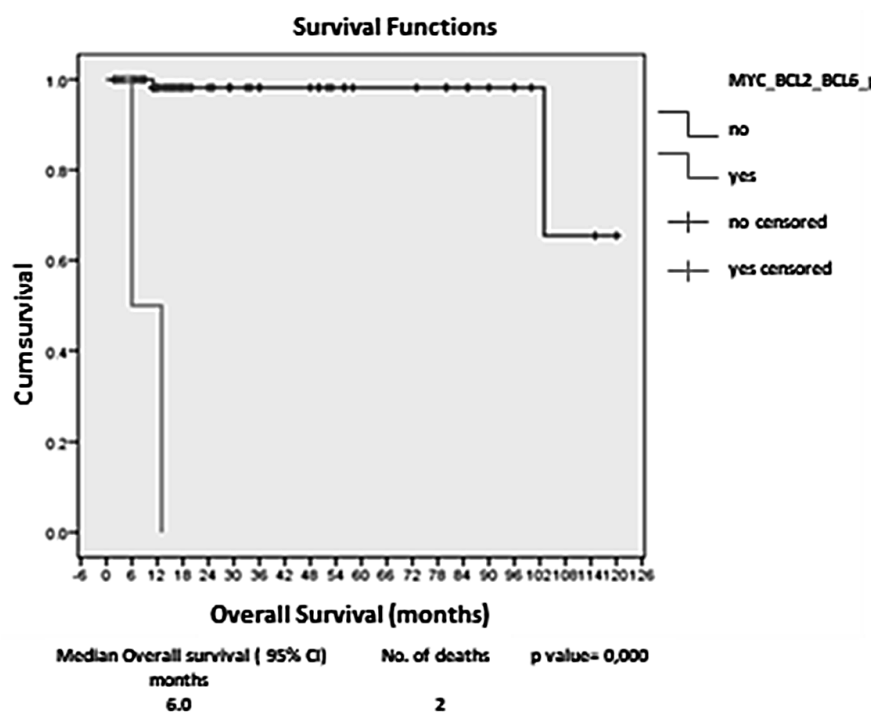

Figure 3. MYC/BCL2/BCL6 Kaplan Meyer curve for overall survival
$16,7 \%$ were non-responsive. The mean survival to death was 13,750 months with median survival of 13.00 months ( $\mathrm{p}$ value $=0,000)($ Figure 1$)$.

Four patients showed positive MYC and BCL6 with 3 deaths within them, only $4,3 \%$ presenting complete therapeutic response and $16,7 \%$ were non-responsive. The mean survival of patients with MYC/BCL6 positivity is 40,667 months with a standard deviation of 2 months, and the median survival is 13 months ( $\mathrm{p}$ value= 0,000) (Figure 2).

As showed the Table 2, of the total patients in the study group, 3 were triple positive MYC / BCL2/BCL6, of which 2 died, 4,3\% have presented complete therapeutic response and 16,7\% were non-responsive. Estimated survival rates for patients who had MYC/BCL2/BCL6 positivity was 9,500 months, with a standard deviation of 4,909 months and the median survival was 6,000 months ( $\mathrm{p}$ value $=0,000$ ) (Figure 3).

Relapse was recorded in 50\% of MYC/ BCL6 dual positivity, 16,7\% of cases with dual positivity MYC/BCL2 and in 33,3\% in patients with triple positivity MYC/BCL2/ BCL6.

\section{Discussion}

The classification of diffuse large B cell lymphoma has been the subject of dynamic evolution during last decades. Our results highlight the well-known difference between clinic-pathological features and the presence of MYC/BCL6/BCL2 dual and triple expression in diffuse large $\mathrm{B}$ cell lymphoma. This type of expression is uncommon but their presence on immunohistochemical stain requires the need for molecular testing due to unfavorable outcome of this group of patients.

The exploratory analysis of patients' age at the time of diagnosis has shown a negative distribution, indicating over $50 \%$ of patients older than the median age (57 years), with male predominance, being an independent prognostic factor.

B symptoms were present in $55 \%$ of patients, unlike the literature in which $40 \%$ of patients with B symptoms are reported. According to the literature, the presence of $B$ symptoms is an independent negative prognostic factor for general survival.

In our study, dual positivity MYC/BCL2, MYC/BCL6 and triple positivity MYC/ BCL6/ BCL2 were correlated with relapses in almost 
$50 \%$ of cases, claiming that this combination is an independent negative factor.

Also, we have found worse overall survival than other studies. Multivariable COX analysis showed that dual and triple expression MYC/BCL2/BCL6 correlates with poor survival and also with treatment response and relapse.

In log rank test univariate cox analysis, presence of this dual and triple expression was associated with poor outcome, whereas tumors without this expression showed a better outcome.

The various studies in Western populations and Chinese patients showed that combined scores MYC/BCL2/BCL6 were correlated with low 5 years survival. Johnson et al. reported MYC over expression as a poor predictor at 3 years in patients treated with RCHOP, but not in patients treated with CHOP, with no mechanisms known. This study, supported by clinical trials, confirms that MYC/BCL2, MYC/ BCL6 or MCL/BCL6 dual and triple positivity represent a subset of patients with high risk clinical and pathological aspects and lower survival, and can be used as markers of prognosis for stratification of patients with DLBCL for new therapies ${ }^{30-32}$.

\section{Conclusions}

All patients with aberrant expression of the three markers should be tested for the prediction of gene translocations ${ }^{33,34}$.

To expand our understanding of dual and triple MYC/BCL2 and BCL6 positivity, more information about genome profiles and cell signaling in larger cohorts is necessary.

\section{Acknowledgements:}

All the authors contributed equally to the presented study and take responsibility for the integrity of the data and the accuracy of the data analysis.

The study was supported by RESEARCH 62 European doctoral context project - contract number: POSDRU/187/1.5/S/156069

\section{Compliance with Ethics Requirements:}

„The authors declare no conflict of interest regarding this article"

„The authors declare that all the procedures and experiments of this study respect the ethical standards in the Helsinki Declaration of 1975, as revised in 2008(5), as well as the national law. Informed consent was obtained from all the patients included in the study"

\section{Refferences}

1. Aisenberg AC. Primary large cell lymphoma of the mediastinum. Semin Oncol, 1999, 26: 251-258.

2. Cesarman E, Chang Y, Moore PS, Said JW, Knowles DM. Kaposi's sarcoma-associated herpesviruslike DNA sequences in AIDS-related body-cavity-based lymphomas. N Engl J Med 1995, 332:1186-1191.

3. Gatter KC, Warnke RA. Intravascular large B-cell lymphoma. World Health Organization Classification of Tumours: Pathology and Genetics of Tumours of Haematopoietic and Lymphoid Tissues, IARC Press, Lyon, 2001, pp. 177-178.

4. Pedersen NT, Christensen BE. Diffuse large B-cell lymphoma: clinical implications of extranodal versus nodal presentation a population-based study of 1575 cases. Br J Haematol 2004; 124: 151-159.

5. Lenz G, Staudt LM. Aggressive lymphomas. N Engl J Med 2010; 362: 1417-1429.

6. Meyer PN, Fu K, Greiner TC, et al. Immunohistochemical methods for predicting cell of origin and survival in patients with diffuse large B-cell lymphoma treated with rituximab. J Clin Oncol 2011; 29: 200-207.

7. Coutinho R, Clear AJ, Owen A, et al. Poor concordance among 9 immunohistochemistry classifiers of cell-of-origin for diffuse large B-cell lymphoma, implications for therapeutic strategies. Clin Cancer Res, 2013, 19:6686-6695.

8. Dalla-Favera R, Bregni M, Erikson J, Patterson D, Gallo RC, Croce CM. Human c-myc onc gene is located on the region of chromosome 8 that is translocated in Burkitt lymphoma cells. Proc Natl Acad Sci USA, 1982, 79:7824-7827.

9. Dang CV, O’Donnell KA, Zeller KI, Nguyen T, Osthus RC, Li F. The c-Myc target gene network. Semin Cancer Biol. 2006, 16: 253-264.

10. Cigudosa JC, Parsa NZ, Louie DC, et al. Cytogenetic analysis of 363 consecutively ascertained diffuse large B-cell lymphomas. Genes Chromosomes Cancer, 1999, 25:123-133.

11. Akasaka T, Akasaka H, Ueda C, et al. Molecular and clinical features of non-Burkitt's, diffuse large-cell lymphoma of B-cell type associated with the c-MYC/immunoglobulin heavy-chain fusion gene. J Clin Oncol, 2000, 18:510-518.

12. Kawasaki C, Ohshim K, Suzumiya J, et al. Rearrangements of bcl-1, bcl-2, bcl-6, and c-myc in diffuse large B-cell lymphomas. Leuk Lymphoma 2001, 42:1099-1106.

13. Chisholm KM, Bangs CD, Bacchi CE, Molina-Kirsch H, Cherry A, Natkunam Y. Expression profiles of MYC protein and MYC gene rearrangement in lymphomas. Am J Surg Pathol. 2015, 39:294-303.

14. Karube K, Campo E. MYC alterations in diffuse large B-cell lymphomas. Semin Hematol. 2015, 52:97-106.

15. Savage KJ, Johnson NA, Ben-Neriah S, et al. MYC gene rearrangements are associated with a poor prognosis in diffuse large B-cell lymphoma patients treated with R-CHOP chemotherapy. Blood, 2009, 114:3533-3537.

16. Johnson NA, Savage KJ, Ludkovski O, et al. Lymphomas with concurrent BCL2 and MYC translocations: The critical factors associated with survival. Blood, 2009, 114:2273-2279.

17. Pedersen MO, Gang AO, Poulsen TS, et al. Double-hit BCL2/MYC translocations in a consecutive cohort of patients with large B-cell lymphoma - a single centre's experience. Eur J Haematol. 2012, 89:63-71.

18. Pillai RK, Sathanoori M, Van Oss SB, Swerdlow SH. Double-hit B-cell lymphomas with BCL6 and MYC translocations are aggressive, frequently extranodal lymphomas distinct from BCL2 double-hit B-cell lymphomas. Am J Surg Pathol, 2013, 37:323-332. 
19. Swerdlow SH, Campo E, Pileri SA, et al. The 2016 revision of the World Health Organization classification of lymphoid neoplasms. Blood, 2016, 127: 2375-2390.

20. Pasqualucci L, Dominguez-Sola D, Chiarenza A, et al. Inactivating mutations of acetyltransferase genes in B-cell lymphoma. Nature, 2011, 471:189-195.

21. Duan S, Cermak L, Pagan JK, et al. FBXO11 targets BCL6 for degradation and is inactivated in diffuse large B-cell lymphomas. Nature, 2012, 481:90-93.

22. Basso K, Dalla-Favera R. Roles of BCL6 in normal and trans formed germinal center B cells. Immunol Rev, 2012;247:172183.

23. Polo JM, Dell'Oso T, Ranuncolo SM, et al. Specific pep tide interference reveals BCL6 transcriptional and oncogenic mechanisms in B-cell lymphoma cells. Nat Med, 2004, 10:1329-1335

24. Cerchietti LC, Ghetu AF, Zhu X, et al. A small-molecule inhibitor of BCL6 kills DLBCL cells in vitro and in vivo. Cancer Cell, 2010, 17:400-411.

25. Cerchietti LC, Hatzi K, Caldas-Lopes E, et al. BCL6 repression of EP300 in human diffuse large B cell lymphoma cells provides a basis for rational combinatorial therapy. J Clin Invest, 2010, 120(12):4569-82.

26. Hans CP, Weisenburger DD, Greiner TC, et al. Confirmation of the molecular classification of diffuse large B-cell lymphoma by immunohistochemistry using a tissue microarray. Blood, 2004,103: 275-282.
27. Petrich AM, Nabhan C, Smith SM. MYC-associated and double-hit lymphomas: a review of pathobiology, prognosis, and therapeutic approaches. Cancer, 2014; 120:3884-3895.

28. Horn H, Ziepert M, Becher C, et al. MYC status in concert with BCL2 and BCL6 expression predicts outcome in diffuse large B-cell lymphoma. Blood, 2013, 121:2253-2263.

29. Remmele W, Stegner HE. Recommendation for uniform definition of an immunoreactive score (IRS) for immunohistochemical estrogen receptor detection (ER-Ica) in breast cancer tissue. Pathologe, 1987, 8 (3):138-140.

30. Horn H, Ziepert M, Becher C, et al. MYC status in concert with BCL2 and BCL6 expression predicts outcome in diffuse large B-cell lymphoma. Blood, 2013, 121: 2253- 2263.

31. Perry AM, Alvarado-Bernal Y, Laurini JA, et al. MYC and BCL2 protein expression predicts survival in patients with diffuse large B-cell lymphoma treated with rituximab. Haematologica, 2014, 98: 255-263.

32.Johnson NA, Slack GW, Savage KJ, et al. Concurrent expression of MYC and BCL2 in diffuse large B-cell lymphoma treated with rituximab plus cyclophosphamide, doxorubicin, vincristine, and prednisone. J Clin Oncol, 2012, 30: 3452-3459.

33. Green TM, Nielsen O, de Stricker K, et al. High levels of nuclear MYC protein predict the presence of MYC rearrangement in diffuse large B-cell lymphoma. Am J Surg Pathol, 2012, 36: 612-619.

34. Chen Y, Han T, Iqbal J, et al. Diffuse large B-cell lymphoma in Chinese patients: immunophenotypic and cytogenetic analyses of 124 cases. Am J Clin Pathol, 2010, 133: 305-313. 